\title{
A New Analytical Procedure for Assay of Lysozyme in Human Tear and Saliva with Immobilized Reagents in Flow Injection Chemiluminescence System
}

\author{
Zheng-Hua Song ${ }^{\dagger}$ and Shuang Hou \\ Department of Chemistry, Northwest University, Xi'an, 710069, China
}

\begin{abstract}
A novel analytical procedure based on chemiluminescence (CL) detection was described for the determination of lysozyme at $\mathrm{ng} \mathrm{ml}^{-1}$ level by using controlled-reagent-release technology in a flow injection system. The analytical reagents involved in the CL reaction, including luminol and periodate, were both immobilized on the anion-exchange resins in the flow injection system. Through water injection, luminol and periodate were eluted from the anion-exchange column to generate the chemiluminescence, which was inhibited in the presence of lysozyme. By measuring the decrease of CL intensity, one could analyze the lysozyme quantitatively. The decrement of CL emission was linear over the logarithm of lysozyme concentration in the range of $30-1000 \mathrm{ng} \mathrm{ml}^{-1}$. A typical analytical procedure, including sampling and washing, could be performed in $0.5 \mathrm{~min}$ at a flow rate of $2.0 \mathrm{ml} \mathrm{min}{ }^{-1}$, giving a throughput of $120 \mathrm{~h}^{-1}$, with a relative standard deviation of less than $3.0 \%$. The proposed method was applied successfully to the determination of lysozyme in human tear and saliva samples, and the recovery was from $92.0 \%$ to $105.7 \%$.
\end{abstract}

(Received April 15, 2002; Accepted September 24, 2002)

\section{Introduction}

Lysozyme (peptioglycan $\mathrm{N}$-acetylmuramoyl hydrolase, E.C. 3.2.1.), which was discovered by Fleming ${ }^{1}$ in 1922, is an enzyme with anti-bacterial action that is found in body fluids. Recently, it was reported that lysozyme is also an effective agent for killing HIV in vitro. ${ }^{2}$

Numerous methods have been reported for the determination of lysozyme. A traditional method was reported in 1946, in which an Ostwald or Uberlohde viscometer was employed for determination of lysozyme by monitoring the decrease in viscosity of various substrates. ${ }^{3}$ Up to now, the most widely used method was chromatography involving HPLC and affinity chromatography. ${ }^{4-8}$ The nephelometric immunoassay has also been developed, with the detection limit of $0.58 \mathrm{mg} \mathrm{ml}^{-1}$ for assay of lysozyme..$^{910}$ In addition, several useful methods have been proposed including fluorimetry, ${ }^{11}$ acoustic wave viscosity sensor ${ }^{12}$ and response surface methodology. ${ }^{13}$

FI chemiluminescence (CL) analysis is becoming increasingly important in various fields thanks to its high sensitivity, rapidity, simplicity and feasibility. ${ }^{14-16}$ The fast oxidation reaction between luminol and periodate in alkaline medium produces a strong CL signal. This CL is greatly inhibited by lysozyme; thus a sensitive CL inhibition assay for lysozyme combined with FI technology is described in this paper. If the $\mathrm{CL}$ reactants were directly introduced into CL cell, it would be undesirable: operational convenience, the simplicity of detection device, and cost, environment and resource considerations. ${ }^{17}$ An effective approach to solve this problem is

† To whom correspondence should be addressed.

E-mail: songzhenghua@hotmail.com to immobilize CL reagents on solid phase. The analytical reagents involved in the $\mathrm{CL}$ reaction, including luminol and periodate, were both immobilized on the anion-exchange column in FI system. Through injection of $100-\mu$ l water, the reagents on the anion-exchange column are eluted from the resins. In the presence of lysozyme, the $\mathrm{CL}$ reaction is inhibited; the amount of lysozyme can then be measured. The $\mathrm{CL}$ emission was correlated with the lysozyme concentration in the range from 30 to $1000 \mathrm{ng} \mathrm{ml}^{-1}$, and the determination could be performed in $0.5 \mathrm{~min}$, including sampling and washing, giving a throughput of $120 \mathrm{~h}^{-1}$ with a relative standard deviation of less than $3.0 \%$. The proposed method offers simple and cheap instrumentation and rapid and reproducible means of detection; it was applied to the determination of lysozyme in human tear and saliva.

\section{Experimental}

\section{Reagents}

All solutions were prepared from analytical-reagent grade chemicals using doubly distilled, deionized water throughout. Lysozyme (Sigma) and luminol (Fluka, Biochemika, Switzerland) were obtained from Xi'an Medicine Purchasing and Supply Station, China. Potassium periodate was purchased from Xi'an Chemical Reagent Plant.

A standard solution of lysozyme $\left(100.0 \mu \mathrm{g} \mathrm{ml}^{-1}\right)$ was stored at $4^{\circ} \mathrm{C}$ and protected from light. Working strength solutions were prepared daily from the above stock solution as required. Luminol was used as supplied to prepare a $0.25 \mathrm{~mol} \mathrm{l}^{-1}$ stock standard solution in $0.5 \mathrm{~mol} \mathrm{l}^{-1} \mathrm{NaOH}$ in a $1000 \mathrm{ml}$ calibrated flask. A $0.04 \mathrm{~mol} \mathrm{l}^{-1}$ stock standard solution of potassium periodate was made by dissolving the solid in distilled water 


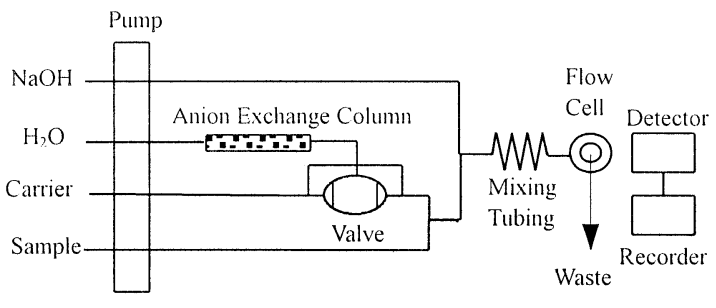

Fig. 1 Schematic diagram of the flow-injection system for lysozyme determination.

and diluting to a $250 \mathrm{ml}$ calibrated flask.

\section{Preparation of immobilized reagents column}

Amberlyst A-27 (1.0 g) was shaken with $50 \mathrm{ml} 0.25 \mathrm{~mol} \mathrm{l}^{-1}$ luminol or $0.04 \mathrm{~mol} \mathrm{l}^{-1}$ potassium periodate for $12 \mathrm{~h}$; then the resin was filtered, washed with doubly distilled water and drystored. The most convenient method to determine the amounts of luminol and potassium periodate immobilized was to measure the losses of these reagents from the immobilization solutions. The concentration was detected at $360 \mathrm{~nm}$ for luminol and at $225 \mathrm{~nm}$ for potassium periodate by UV-Vis. The amounts of luminol and periodate immobilized were $1.99 \pm 0.02$ mmol g-1 $(n=4)$ and $1.01 \pm 0.01 \mathrm{mmol} \mathrm{g}^{-1}(n=3)$ resin, respectively. A column with immobilized reagents is prepared by packing a glass column (i.d. $3 \mathrm{~mm}$ and total volume of about $0.5 \mathrm{ml})$ with resins containing immobilized luminol $(0.05 \mathrm{~g})$ and potassium periodate $(0.10 \mathrm{~g})$; these were mixed together, and plugged with glass wool at both ends to prevent the resin from leaking.

\section{Apparatus}

Figure 1 depicts CL-FIA manifold for the determination of lysozyme. A peristaltic pump (Shanghai Meter Electromotor Plant, Model ND-15, $15 r \mathrm{~min}^{-1}$ ) was used to generate the flows. PTFE tubing (1 mm i.d.) was used throughout the flow system. A six-way valve for quantitative injection of the stream of reagents was employed. One hundred microliters of eluant, flowing through the immobilized reagents column and containing quantitatively eluted luminol and periodate, was injected into the carrier stream. Before reaching the flow cell, the streams of luminol, periodate, sodium hydroxide and analyte were combined in a mixing tube $(50 \mathrm{~mm}$ in length). To provide highly efficient collection of the chemiluminescence, a specially constructed T-spiral cell was employed. This flow-through cell was mounted directly in front of the photomutiplier tube (PMT) (HAMAMATSU, Model IP28). Extreme precautions were taken to ensure that the sample compartment and PMT were light-tight. The CL signal produced in flow was detected without wavelength discrimination, and the PMT output was amplified and quantified by a luminosity meter (Xi'An Remax Electronic Science-Tech. Co., Ltd., China, Model GD-1) connected to a recorder (Shanghai Dahua Instrument and Meter Plant, Model XWT-206).

\section{Procedures}

The carrier water and the solutions $(\mathrm{NaOH}$, sample and eluant) were propelled at a constant flow rate on each flow line. The pump was started to wash the whole flow system until a stable baseline was recorded. Then $100 \mu \mathrm{l}$ of water, flowing through the immobilized reagents column and containing quantitatively eluted luminol and periodate, was injected into the carrier stream, and mixed with the sample stream. The

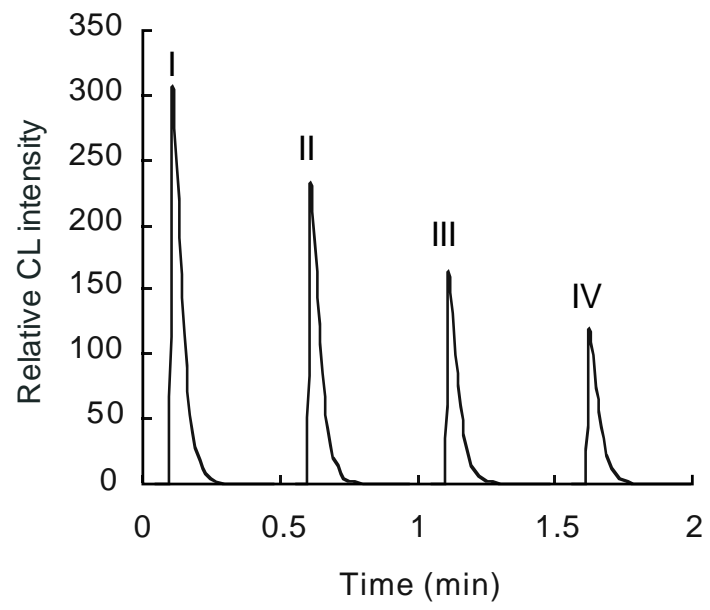

Fig. 2 CL time profile in the batch system. I, CL intensity in the absence of lysozyme; II, CL intensity in the presence of lysozyme (50 $\mathrm{ng} \mathrm{ml} \mathrm{m}^{-1}$; III, CL intensity in the presence of lysozyme (150 $\left.\mathrm{ng} \mathrm{ml}^{-1}\right)$; $\mathrm{IV}, \mathrm{CL}$ intensity in the presence of lysozyme $\left(500 \mathrm{ng} \mathrm{ml}^{-1}\right)$.

mixed solution was delivered into the CL cell, and the peak height of the CL signal was detected with the PMT and the luminometer. The concentration of sample was quantified by the decrease of CL intensity, $\Delta I=I_{\mathrm{o}}-I_{\mathrm{s}}$, where $I_{\mathrm{s}}$ and $I_{\mathrm{o}}$ are CL signals in the presence and in the absence of lysozyme, respectively.

\section{Results and Discussion}

\section{Time profile of the CL reaction}

Before carrying out the flow injection method, we used the batch method for the CL profiles. Without any special eluant, the mixture of luminol and periodate rinsed by water gave an evident CL signal. As illustrated in Fig. 2, the CL intensity reached a maximum $12 \mathrm{~s}$ after injection, and then disappeared within $25 \mathrm{~s}$. On joining of the sample into the above mixing solution, a decreased CL signal was recorded. The decrement of $\mathrm{CL}$ emission was proportional to the concentration of lysozyme.

\section{Designation for the FI-CL system}

The assay was carried out by a continuous-flow mode, and two different manifolds were designed. Through injection of $(100-\mu \mathrm{l})$ eluant $\left(1.0 \times 10^{-4} \mathrm{~mol} \mathrm{l}^{-1}\right.$ of $\left.\mathrm{Na}_{3} \mathrm{PO}_{4}\right)$, the reagents on the anion-exchange resin column were eluted. In the presence of lysozyme, the CL intensity was inhibited, and the decrease of $\mathrm{CL}$ intensity was recorded. While the column with immobilized reagents was put in front of the injection valve (Fig. 1) or behind the injection valve, two significantly different results were observed. The whole analysis process, including sampling and washing, could be accomplished in $0.5 \mathrm{~min}$ while the column with immobilized reagents was put in front of the injection valve, whereas it took about 2.5 min using another one with a higher background. Therefore, the flow system as shown in Fig. 1 was regarded as optimum in efficiency for subsequent work.

\section{Selection of eluant}

Different eluants $(100-\mu 1$ each) were injected through the column with immobilized reagents; they released different amounts of luminol and periodate, thus producing the CL 
Table 1 Character of eluants for lysozyme determination ${ }^{\mathrm{a}}$

\begin{tabular}{crrrrr}
\hline \multirow{2}{*}{$\begin{array}{c}\text { Type of CL } \\
\text { intensity }\end{array}$} & $\mathrm{H}_{2} \mathrm{O}$ & $\mathrm{NaCl}$ & $\mathrm{Na}_{2} \mathrm{CO}_{3}$ & $\mathrm{Na}_{2} \mathrm{SO}_{4}$ & $\mathrm{Na}_{3} \mathrm{PO}_{4}$ \\
\cline { 2 - 6 } & 226 & 253 & 109 & 457 & 378 \\
I & 202 & 224 & 102 & 409 & 356 \\
II & 24 & 29 & 7 & 48 & 22 \\
III & 24 & & \\
\hline
\end{tabular}

a. The concentration of solution was $1.0 \times 10^{-4} \mathrm{~mol} \mathrm{l}^{-1}$.

I, CL intensity in the absence of lysozyme; II, CL intensity in the presence of $50 \mathrm{ng} \mathrm{ml}^{-1}$ lysozyme; III, the decrease of CL intensity.

emission. In this flow system, the characteristics of several eluants including $\mathrm{NaCl}, \mathrm{Na}_{2} \mathrm{CO}_{3}, \mathrm{Na}_{2} \mathrm{SO}_{4}, \mathrm{Na}_{3} \mathrm{PO}_{4}$ and $\mathrm{H}_{2} \mathrm{O}$ were evaluated and the results are shown in Table 1. Sodium sulfate gives a maximum $\mathrm{CL}$ emission while sodium carbonate shows some inhibitive effects on the CL reaction. Nevertheless, it was observed that a continuous flow of eluant through the column results in a rather short lifetime of column down to only a few hours. The immobilized luminol and periodate anions on the anion exchange resin undergo dissociation with water, thus releasing trace amounts of luminol and periodate from the column, and the decrease of CL signal could be easily observed. In this case, the column with immobilized reagents could be used over ten days. Considering the higher CL intensity and longer lifetime of the column, we used water as eluant in subsequent work.

\section{Effect of $\mathrm{pH}$ on $\mathrm{CL}$ and column lifetime}

The best $\mathrm{pH}$ of eluant (water) on the performance of the system was evaluated. Along with the increase of $\mathrm{pH}$ in eluant, the CL intensity increased while the lifetime of the column decreased considerably (Fig. 3). This phenomenon is probably because the quantities of hydroxide ions in eluant were increasing. pH 6.5 was then chosen as a compromise between lifetime and a sufficient CL intensity. In this case, the column with immobilized CL reagents could be used more than $120 \mathrm{~h}$ in the continuous-injection system.

\section{Effect of molar ratio of immobilized luminol and periodate}

To examine the influence of the molar ratio of luminol and periodate, we packed resins $(0.15 \mathrm{~g})$ with different mixing ratios into columns with same internal diameter and volume. By injection of distilled water at a fixed volume of $100 \mathrm{ml}$, different amounts of luminol and periodate were eluted from the resins and CL signals with different intensities were emitted. As Fig. 4 shows, the CL intensity dropped drastically from beginning to next day, then it went down slowly. The most stable CL signal was found with a molar ratio of 1:2 (luminol to periodate) and a middling CL intensity is in favor of measuring an inhibitory effect of lysozyme on CL reaction.

\section{Effect of $\mathrm{NaOH}$ concentration}

Owing to the nature of the luminol reaction, which is more favored under alkaline media, the concentration of sodium hydroxide was optimized to improve the sensitivity for lysozyme. It was found that, if the concentration of $\mathrm{NaOH}$ is higher than $0.2 \mathrm{~mol} \mathrm{l}^{-1}$, there is a scattering effect in flow cell due to the discrepancy between refractive index of various components, and an $\mathrm{NaOH}$ concentration less than $0.05 \mathrm{~mol} \mathrm{l}^{-1}$ led to an apparent decrease in $\Delta I$. An alkaline media of $0.1 \mathrm{~mol}$ $\mathrm{l}^{-1} \mathrm{NaOH}$ provided strong and stable CL signal and optimum

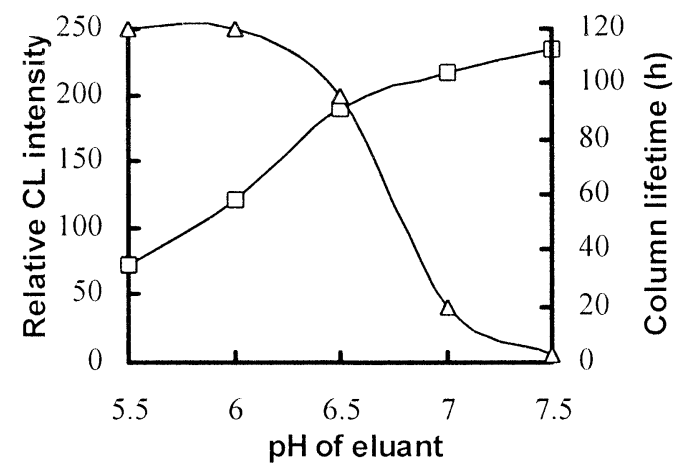

Fig. 3 Effect of eluant pH on CL intensity ( $\square$ ) and effect of eluant $\mathrm{pH}$ on column lifetime $(\Delta)$

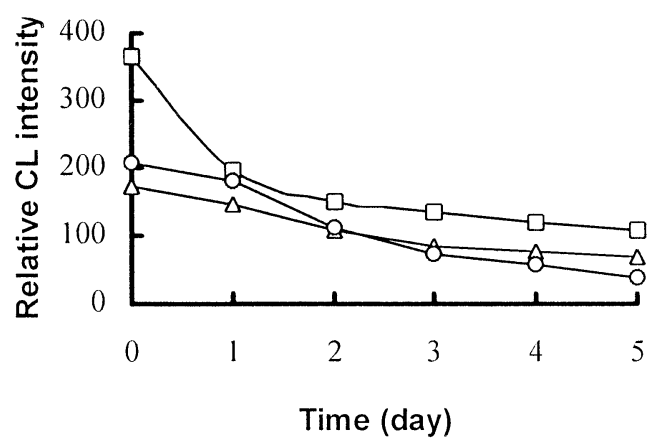

Fig. 4 Effect of molar ratio on CL intensity and the lifetime of column. $\square, 1: 1 ; 0,1: 2 ; \triangle, 1: 2$.

sensitivity for analysis.

\section{Effect of flow rate and the length of mixing tubing}

The CL signal was also dependent on the flow rate of carrier and eluant. The signal-to-noise ratio increased at a higher flow rate. Nevertheless, the high flow rate could lead to an unstable baseline and to a shortening of the column lifetime. The lower flow rate caused broadening of the peak and slowing down of the sampling rates. A rate of $2.0 \mathrm{ml} \mathrm{min}{ }^{-1}$ was then chosen as a compromise between good precision and analytical efficiency. A $50 \mathrm{~mm}$ length of mixing tubing was determined to be optimal, affording experimental results with good sensitivity.

\section{Performance of the system for lysozyme}

Lysozyme, as an inhibitor, is detected linearly by the CL reaction between small amounts of luminol and periodate. The optimized system exhibited a detection limit of $10 \mathrm{ng} \mathrm{ml}^{-1}$, and the decrease of CL intensity was linear with the logarithm of lysozyme concentration in the range from 30 to $1000 \mathrm{ng} \mathrm{ml}^{-1}$. The regression equation was $Y_{\mathrm{CL}}=23.04 \log C_{\text {lysozyme }}-21.969, r^{2}$ $=0.9996$.

The observed relative standard deviation (RSD) at all concentrations within the linear range was less than 3.0\%. At a flow rate of $2.0 \mathrm{ml} \mathrm{min}{ }^{-1}$, a typical determination of lysozyme, including sampling and washing, could be performed in $25 \mathrm{~s}$ and a sample throughput of 120 times per hour was achieved.

\section{Selectivity studies}

The selectivity study of the proposed method for lysozyme was focused on some common metal ions and organic compounds. The tolerable concentration excesses of other 
Table 2 Calibration graph of lysozyme at different temperatures ${ }^{\mathrm{a}}$

\begin{tabular}{ccccc}
\hline Temperature/K & Concentration/ng ml ${ }^{-1}$ & Regression equation & $R^{2}$ & $\begin{array}{c}\text { RSD, } \% \\
\left(30 \mathrm{ng} \mathrm{ml}^{-1}, n=5\right)\end{array}$ \\
\hline 298 & $30-1000$ & $\mathrm{Y}=23.04 \log C-21.969$ & 0.9996 & 2.14 \\
308 & $30-1000$ & $\mathrm{Y}=29.74 \log C-33.672$ & 0.9956 & 2.18 \\
313 & $30-1000$ & $\mathrm{Y}=31.90 \log C+4.8039$ & 0.9974 & 2.31 \\
323 & $30-1000$ & $\mathrm{Y}=22.01 \log C-6.1402$ & 0.9936 & 2.23 \\
\hline
\end{tabular}

a. The average of five determinations.

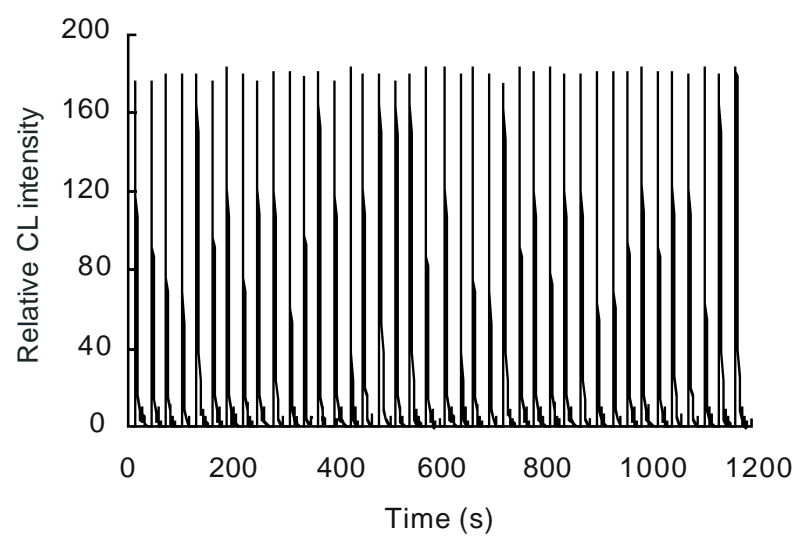

Fig. 5 CL signals in the absence of lysozyme.

species caused no interferences (relative error less than $5 \%$ in the presence of $50 \mathrm{ng} \mathrm{ml}^{-1}$ lysozyme): 600 for $\mathrm{NH}_{4}^{+}, \mathrm{Mg}^{2+}, \mathrm{Ca}^{2+}$, $\mathrm{Zn}^{2+}, \mathrm{Ni}^{2+}, \mathrm{Mn}^{2+}, \mathrm{Cr}^{3+}$, borate, oxalate, methanol, ethanol, urea, glucose, sucrose, gelatine, starch, dextrin, 200 for mannitol, 10 for $\mathrm{Cu}^{2+}, 2$ for $\mathrm{Fe}^{2+} / \mathrm{Fe}^{3+}$. Compounds abundant in human tears and saliva such as salt, lipid and proteins caused no obvious interference with the determination.

\section{Operational stability and lifetime of the column}

One hundred microliters of eluant (water, $\mathrm{pH}$ 6.0) was flowinjected through the system and the CL intensity $\left(I_{0}\right)$ was recorded to test the operational stability and the lifetime of the immobilized reagents column. As Fig. 5 shows, the CL signal of blank became rather stable in a short time $(20 \mathrm{~min})$. The experiment lasted for eight days and the system was tested for over $8 \mathrm{~h}$ per day; the average CL intensity was calculated in ten spots check determinations. It was found that the CL intensity in the first $5 \mathrm{~h}$ was very unstable. With the increase of soakage time, the interaction between water and resin tended to form a kind of equilibrium and the CL signal $\left(I_{0}, I_{\mathrm{s}}\right.$ and $\left.\Delta I\right)$ came to be steady. However, the column could be used stably for over eight days with an RSD less than $3.0 \%$.

\section{Interesting phenomena-effect of temperature}

Ibrahim et al. ${ }^{18}$ reported that heat denaturation of lysozyme caused by increasing temperature results in the progressive loss of enzymatic activity, while its antimicrobial action towards Gram-negative bacteria is greatly promoted. In the present work, the effect of temperature on the solid lysozyme was also tested. One crystal of lysozyme was kept thermostatically at $298 \mathrm{~K}, 308 \mathrm{~K}, 313 \mathrm{~K}$ or $323 \mathrm{~K}$ in an atmosphere of inertia gas (argon) for $2 \mathrm{~h}$, respectively and then a series of standard solutions were prepared. These were detected under the optimized conditions to test the linearity of lysozyme. Interestingly, it was found that lysozyme still has activation
Table 3 The results of measuring different solutions by UV at $254 \mathrm{~nm}$

\begin{tabular}{lc}
\hline \multicolumn{1}{c}{ Species $^{\mathrm{a}}$} & $A^{\mathrm{b}}$ \\
\hline Periodate & 0.019 \\
Lysozyme & 0.203 \\
Periodate + lysozyme & 0.311 \\
\hline
\end{tabular}

a. The same concentration and injection volume $\left(5.0 \times 10^{-5} \mathrm{~mol} \mathrm{l}^{-1}\right.$, $25 \mu \mathrm{l})$.

b. The average of five determinations.

after heating at $323 \mathrm{~K}$ for $2 \mathrm{~h}$. As Table 2 shows, the CL emission was correlated with the lysozyme concentration in the range from 30 to $1000 \mathrm{ng} \mathrm{ml}^{-1}$ in the temperature varying from $298 \mathrm{~K}$ to $323 \mathrm{~K}$. It is also worth noticing that at $313 \mathrm{~K}$ the inhibitory effect of lysozyme on $\mathrm{CL}$ is more sensitive than that at other temperatures.

\section{Possible mechanism of the reaction}

Periodate oxidation has become one of the most important categories of the chemical reactions involving proteins. ${ }^{19-23}$ Recently, Ondracek et al. ${ }^{24}$ also reported the structure-function relationships of lysozyme with periodate. In view of the widespread use of periodate in protein modification, the mechanism of periodate oxidizing certain amino acids in lysozyme is not clear up to now.

In order for us to get an idea about the lysozyme quenching the CL generated by periodate and luminol, the UV $(254 \mathrm{~nm})$ of the lysozyme, periodate and their mixed solutions were each examined by a series of experiments. The results, listed in Table 3, indicated that the adsorption of the mixed solution of lysozyme and periodate was much increased and even higher than the total of that of the lysozyme and periodate. The product of the reaction between periodate and lysozyme did not react with luminol chemiluminescently. Feeney ${ }^{19,20}$ and De la Llosa $^{21}$ reported that periodate could oxidize the methionine in proteins. Therefore, it may be concluded that methionine in lysozyme reacted with periodate. The inhibition mechanism is presented below:

$$
\begin{aligned}
& \text { methionine (in lysozyme) } \stackrel{\mathrm{IO}_{4}^{-}}{\longrightarrow} \text { sulfoxide }{ }^{19} \\
& \text { (in lysozyme) }
\end{aligned}
$$

periodate + luminol $\stackrel{\mathrm{OH}^{-}}{\longrightarrow}$ aminophthalate $+h v$

$$
\left(\lambda_{\max } 425 \mathrm{~nm}\right)
$$

\section{Applications}

\section{Determination of lysozyme in human tears and saliva}

It is well known that lysozyme is abundant in tears, saliva, and 
Table 4 Results of lysozyme in human tear samples ${ }^{\mathrm{a}}$

\begin{tabular}{|c|c|c|c|c|c|c|}
\hline Sample ${ }^{b}$ & $\begin{array}{c}\text { Lysozyme } \\
\text { supplement/ng ml }\end{array}$ & Found/ng ml ${ }^{-1}$ & $\mathrm{RSD}, \%(n=5)$ & $\begin{array}{c}t \\
t_{0.05,5}=2.57\end{array}$ & Recovery, \% & Content in tear/mg ml $\mathrm{ml}^{-1}$ \\
\hline \multirow[t]{2}{*}{1} & 0 & 53 & 2.55 & 2.13 & 104.7 & 1.59 \\
\hline & 50 & 105 & 1.95 & & & \\
\hline \multirow[t]{2}{*}{2} & 0 & 42 & 2.65 & 1.73 & 94.3 & 1.25 \\
\hline & 50 & 89 & 1.99 & & & \\
\hline \multirow[t]{2}{*}{3} & 0 & 66 & 2.41 & 1.96 & 94.0 & 2.11 \\
\hline & 50 & 113 & 1.31 & & & \\
\hline \multirow[t]{2}{*}{4} & 0 & 62 & 2.47 & 2.07 & 102.3 & 1.99 \\
\hline & 50 & 113 & 1.29 & & & \\
\hline \multirow[t]{2}{*}{5} & 0 & 69 & 2.38 & 1.62 & 94.3 & 1.53 \\
\hline & 35 & 102 & 1.97 & & & \\
\hline \multirow[t]{2}{*}{6} & 0 & 76 & 2.12 & 1.47 & 94.2 & 1.64 \\
\hline & 35 & 109 & 1.42 & & & \\
\hline \multirow[t]{2}{*}{7} & 0 & 72 & 2.19 & 1.56 & 102.8 & 1.61 \\
\hline & 35 & 108 & 1.52 & & & \\
\hline \multirow[t]{2}{*}{8} & 0 & 71 & 2.21 & 1.33 & 105.7 & 1.67 \\
\hline & 35 & 108 & 1.82 & & & \\
\hline
\end{tabular}

a. The average of five determinations. b. Eight volunteers.

Table 5 Results of lysozyme in human saliva samples ${ }^{a}$

\begin{tabular}{|c|c|c|c|c|c|c|}
\hline Sample $^{\mathrm{b}}$ & $\begin{array}{c}\text { Lysozyme } \\
\text { supplement/ng ml }\end{array}$ & Found/ng ml ${ }^{-1}$ & $\mathrm{RSD}, \%(n=5)$ & $\begin{array}{c}t \\
t_{0.05,5}=2.57\end{array}$ & Recovery, \% & Content in saliva $/ \mu \mathrm{g} \mathrm{ml}^{-1}$ \\
\hline \multirow[t]{2}{*}{1} & 0 & 43 & 2.31 & 1.73 & 98.0 & 10.8 \\
\hline & 50 & 92 & 2.03 & & & \\
\hline \multirow[t]{2}{*}{2} & 0 & 52 & 2.28 & 0.97 & 92.0 & 11.9 \\
\hline & 50 & 98 & 1.79 & & & \\
\hline \multirow[t]{2}{*}{3} & 0 & 39 & 2.45 & 1.24 & 104.0 & 9.6 \\
\hline & 50 & 91 & 2.21 & & & \\
\hline \multirow[t]{2}{*}{4} & 0 & 40 & 2.38 & 1.31 & 96.0 & 10.1 \\
\hline & 50 & 88 & 2.23 & & & \\
\hline \multirow[t]{2}{*}{$5^{c}$} & 0 & 97 & 1.75 & 1.17 & 92.0 & 24.4 \\
\hline & 50 & 143 & 1.44 & & & \\
\hline
\end{tabular}

a. The average of five determinations. b. Five volunteers. c. The patient of stomatitis.

serum..$^{25}$ The tear and saliva samples were collected from ten volunteers. Without any pretreatment procedures, sample solutions were diluted with water into the working range of concentration for determination of lysozyme. Following the procedure detailed in the Experimental section, the proposed method was applied with preliminary success to the determination of lysozyme in human tears and saliva. In order to evaluate the validity of the proposed method for the determination of lysozyme in human tears and saliva, recovery studies were carried out on samples to which known amounts of lysozyme had been added; the experimental data were verified by t-test. The results of trial determinations are summarized in Tables 4 and 5, with relative standard deviations of less than $3.0 \%$. The contents of lysozyme are 1.3 to $2.1 \mathrm{mg} \mathrm{ml}^{-1}$ in human tear and 9.6 to $24.4 \mu \mathrm{g} \mathrm{ml}^{-1}$ in human saliva, the recoveries varying from 94.0 to $105.7 \%$ in human tears and 92.0 to $104.0 \%$ in human saliva. The contents of salivary lysosyme agreed with values in the literature. ${ }^{25,26}$

\section{Conclusions}

Within this work, a sensitive and convenient analytical method, using controlled-reagent-release technology in flow injection system, is set up for determination of lysozyme in human tears and saliva by its inhibitory effect on CL. As well, incorporation of the immobilized reagents column into the FIA manifold offers satisfactory stability, good reproducibility and precision in the analysis.

\section{References}

1. A. Fleming, Proc. Royal Soc. London, Ser. B, 1922, 93, 306.

2. S. Lee-Huang, P. L. Huang, and Y. Sun, Proc. Natl. Acad. Sci., 1999, 96, 2678.

3. K. Meyer, E. Hahnel, and A. Steinberg, J. Biol. Chem., 1946, 163, 733 .

4. N. Sasagawa, K. Saito, K. Sugita, S. Kanori, and T. Sugo, J. Chromatogr., 1999, 848(1-2), 161.

5. C. L. Liu and S. S. Verma, J. Chromatogr., 1999, 835(1 2), 93.

6. R. Ghosh and Z. F. J. Cui, Liq. Chromatogr. Relat. Technol., 2000, 23, 1619.

7. Q. Luo, J. D. Andrade, and K. D. Caldwell, J. Chromatogr., 1998, 816, 97.

8. M. Grasselli, S. A. Cameri, A. A. Naiarro del Canizo, and 
O. Cascone, J. Sci. Food Agric., 1999, 79, 333.

9. M. Caballero, R. Ruiz, M. Marquez de Prado, M. Seco, L. Borque, and J. F. Escanero, J. Clin. Lab. Anal., 1999, 13, 301.

10. P. Montagne, M. L. Cuilliere, C. Mole, M. C. Bene, and G. Faure, Clin. Chem., 1998, 44, 1610.

11. B. Gala, A. Gomez-Hens, and D. Perez-Bendito, Talanta, 1996, 43, 1413.

12. L. L. Bao, X. G. Qu, H. M. Chen, X. L. Su, S. Z. Yao, and W. Z. Wei, Mikrochim. Acta, 1999, 132, 61.

13. S. Jarudilokkul, L. H. Popperborg, and D. C. Stuckey, Sep. Sci. Technol., 2000, 35, 503.

14. Z. H. Song, Z. J. Zhang, and W. Z. Fan, Acta Chim. Sin., 1998, 56, 1207.

15. Z. H. Song and L. Wang, Anal. Lett., 2000, 33, 2767.

16. Z. H. Song and L. Wang, Microchem. J., 2001, 68, 47.

17. A. Kuniyoshi, K. Hatta, T. Suzuki, A. Masuda, and M. Yamada, Anal. Lett., 1996, 29, 673.

18. H. R. Ibrahim, S. Higashiguchi, L. R. Juneja, M. Kim, and
T. Yamamoto, J. Agric. Food Chem., 1996, 44, 1416.

19. R. B. Yamasaki, D. T. Osuga, and R. E. Feeney, Anal. Biochem., 1982, 126, 183.

20. W. S. Wong, M. M. Kristjansson, D. T. Osuga, and R. E. Feeney, Int. J. Pept. Protein Res., 1985, 26, 55.

21. P. De la Llosa, A. El Abed, and M. Roy, Can. J. Biochem., 1980, 58,745 .

22. T. Kawakami, K. Akaji, and S. Aimoto, Org. Lett., 2001, 3, 91403.

23. K. F. Geoghegan, M. J. Emery, W. H. Martin, A. S. McColl, and G. O. Daumy, Bioconjug. Chem., 1993, 4, 537.

24. J. Ondracek, F. Jursik, J. Brynda, P. Rezacova, and J. Sedlacek, Protein data bank, 2001 (http://www.rcsb.org/pdb/cgi/statusQuery.cgi?use_or=lysoz yme;pdb_id=lysozyme;title=lysozyme; exact=0).

25. E. F. Osserman, J. Mol. Biol., 1969, 46, 211.

26. C. S. P. Tsang and L. P. Samaranayake, Oral Diseases, 1999, 5, 241. 